\title{
Ascension Island as a mid-Atlantic developmental habitat for juvenile hawksbill turtles
}

\author{
SAM B. WEBER ${ }^{1,2}$, NICOLA WEBER ${ }^{1,2}$, BRENDAN J. GODLEY ${ }^{2}$, TARA PELEMBE ${ }^{3}$, STEDSON STROUD $^{1}$, \\ NATASHA WILLIAMS ${ }^{1}$ AND ANNETTE C. BRODERICK ${ }^{2}$ \\ ${ }^{1}$ Ascension Island Government Conservation Department, Georgetown, Ascension Island, ASCN 1ZZ, British Overseas Territory, \\ ${ }^{2}$ Centre for Ecology and Conservation, College of Life \& Environmental Sciences, University of Exeter, Cornwall Campus, Penryn \\ TR1o 9FE, UK, ${ }^{3}$ Joint Nature Conservation Committee, Monkstone House, City Road, Peterborough PE1 1JY, UK \\ *These authors made equal contributions to the manuscript.
}

\begin{abstract}
Ascension Island in the South Atlantic Ocean is renowned for its globally-important nesting population of green turtles (Chelonia mydas) that has been the subject of long-term research. By comparison, very little is known about the apparently small population of hawksbill turtles (Eretmochelys imbricata) that have been recorded in its waters, thousands of kilometres from known nesting beaches. Here, we collate 10 years of in-water tagging data, opportunistic public sighting records and underwater observations to provide a baseline for future research, and present preliminary data on habitat use derived from two individuals fitted with GPS transmitters. Although public sightings were inevitably biased towards popular recreation areas, the resulting distribution suggests that hawksbill turtles occur year round in Ascension Island's waters along the entire $65 \mathrm{~km}$ of coastline. Hawksbills were observed feeding on benthic algae and encrusting sponges, and were frequently seen scavenging on fish discards around the Island's pier at night aided by anthropogenic lighting. Between 2003 and 2013, 35 turtles were captured, measured, tagged and then released. Curved carapace lengths ranged from 33.5 to $85 \mathrm{~cm}$ (mean = $48.8 \mathrm{~cm}$ ) indicating that most (if not all) individuals encountered around Ascension are post-pelagic juveniles. Four individuals were recaptured at least once giving a mean minimum residence time of $4.2 \mathrm{yr}$ (range: $2.8-7.3 \mathrm{yr}$ ) and a mean growth rate of $2.8 \mathrm{~cm} \mathrm{yr}^{-1}$. Turtles fitted with Fastloc ${ }^{\mathrm{TM}}$ GPS devices remained at Ascension Island for the duration of the study $\left(>90\right.$ days) and occupied restricted home ranges with an average area of $2.5 \mathrm{~km}^{2}$ and an average 'core use area' (50\% utilization distribution) of $0.05 \mathrm{~km}^{2}$. Together, these results suggest that Ascension Island serves as a mid-Atlantic developmental habitat for benthic-feeding, juvenile hawksbill turtles on extended oceanic migrations before recruiting to their adult foraging grounds, likely to be located in Brazil or tropical West Africa.
\end{abstract}

Keywords: marine turtle, life history, home range, growth rate, South Atlantic

Submitted 3 June 2014; accepted 25 July 2014; first published online 15 September 2014

\section{INTRDDUCTION}

Marine turtles have complex life histories characterized by long developmental migrations and multiple ontogenetic shifts in diet and habitat use (Musick \& Limpus, 1997; Bolten, 2003). Knowledge about the adult life stage is reasonably welladvanced for most species. However, many details of the years spent as juveniles are only recently emerging (e.g. Meylan et al., 2011; Witherington et al., 2012; Putman \& Naro-Maciel, 2013; Mansfield et al., 2014). After hatching on tropical and sub-tropical sand beaches, neonates embark on an oceanic dispersal phase that has often been referred to as 'the lost years' due to infrequent sightings (Carr, 1980). This is the least understood life stage, but it appears that posthatchlings are epipelagic and obtain food and shelter by associating with floating mats of vegetation or other debris

Corresponding author:

S.B. Weber

Email: sam.weber@ascension.gov.ac entrained in ocean currents (Witherington et al., 2012; Mansfield et al., 2014). Movements during this time are largely determined by ocean circulation patterns, but young turtles may actively position themselves to ensure transport into favourable areas (Mansfield et al., 2014; Putman et al., 2014).

Once they have attained sufficient size and can effectively regulate their buoyancy, most juvenile green (Chelonia mydas), hawksbill (Eretmochelys imbricata), Kemp's ridley (Lepidochelys kempii) and loggerhead (Caretta caretta) turtles leave the oceanic zone and recruit to neritic feeding habitats where they assume a species-specific benthic diet (Bolten, 2003). Although adults and post-pelagic juveniles sometimes occupy the same foraging areas, in many cases the transition to a neritic lifestyle appears to be a multistage process, with individuals passing through one or more intermediate habitats that are geographically distinct from both pelagic nursery and adult foraging habitats (Musick \& Limpus, 1997; Meylan et al., 2011). The term 'developmental habitat' has been used to describe these staging areas, which are characterized by a predominance of benthic-feeding 
juveniles originating from multiple nesting stocks and exhibiting a degree of residency and site fidelity (Meylan et al., 2011). Developmental habitats have been described for at least four species of marine turtle in the Atlantic and Indo-Pacific and may constitute a normal part of the life cycle of most chelonid sea turtles (Meylan et al., 2011).

In this study, we report on a previously uncharacterized developmental habitat for hawksbill turtles in the central Atlantic Ocean. The hawksbill turtle has a circumglobal distribution in tropical waters of the Atlantic, Indian and Pacific Oceans but has undergone dramatic reductions in population size across its range due to overharvesting for meat, shells and eggs (Mortimer \& Donnelly, 2008). In the Atlantic, significant nesting populations $\left(>_{1000}\right.$ nests $\mathrm{yr}^{-1}$ ) now only occur in the Caribbean (Mexico, Barbados, the Bahamas and Cuba) and Brazil (Mortimer \& Donnelly, 2008). Particle drift models and genetic studies suggest that neonates and juveniles originating from these western Atlantic rookeries frequently undertake extensive trans-Atlantic migrations before being transported back to neritic feeding grounds in the Americas (Proietti et al., 2014; Putman et al., 2014). Numerous juveniledominated developmental habitats for hawksbill turtles have now been described in the Caribbean and their ecology has been well studied (Diez \& van Dam, 2002; Blumenthal et al., 2009a; Meylan et al., 2011; Scales et al., 2011; Berube et al., 2012; Hart et al., 2012, 2013; Wood et al., 2013). By comparison, relatively little is known about immature stages elsewhere in the Atlantic. Although several hawksbill developmental habitats have been identified in Brazil and tropical West Africa, most studies have focused on determining the natal origins of these feeding aggregations rather than on establishing ecological profiles (Monzón-Argüello et al., 2010, 2011; Vilaça et al., 2013; Proietti et al., 2014; Putman et al., 2014; but see Proietti et al., 2012).

Lying close to the Mid-Atlantic Ridge, the tiny British Overseas Territory of Ascension Island is renowned for its globally-important nesting population of green turtles that migrate more than $2000 \mathrm{~km}$ from feeding grounds along the Brazilian coastal shelf (Broderick et al., 2006; Figure 1). However, the Island also supports a small population of juvenile hawksbill turtles about which very little is known. Recent work suggests that $85 \%$ of hawksbills observed in Ascension

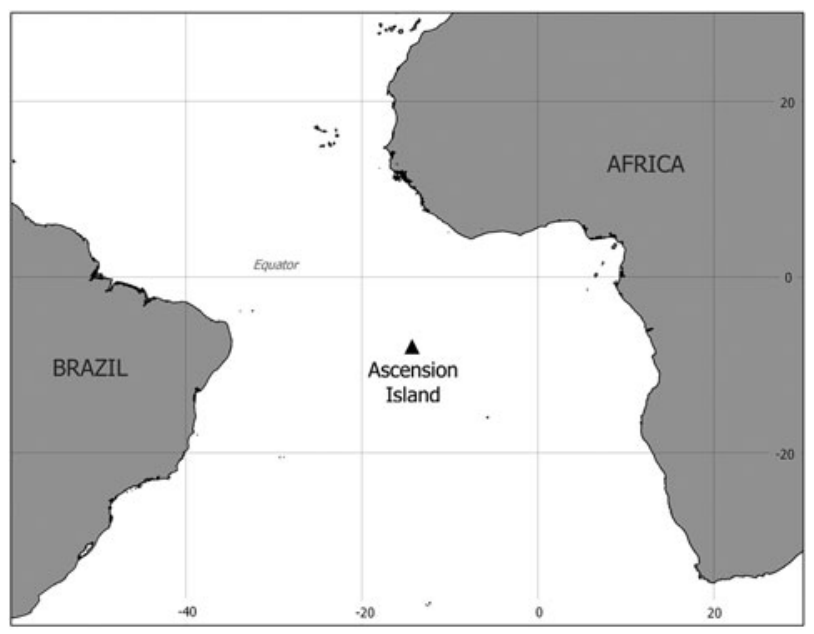

Fig. 1. Geographical location of Ascension Island.
Island's waters originate from nesting populations in northeastern Brazil, with the remainder linked to smaller rookeries in West Africa (e.g. São Tomé and Principe) and potentially even the Indian Ocean (Putman et al., 2014). With the exception of this study, however, published information relating to hawksbills at Ascension Island amounts to a handful of brief anecdotes, with no detailed accounts of their ecology (Ashmole \& Ashmole, 200o). Here, we summarize available information on the spatio-temporal distribution, residence times, growth rates and diets of hawksbill turtles at Ascension Island obtained through 10 years of public sightings records, opportunistic in-water tagging and diver observations. In addition, we present preliminary assessments of habitat use and home range size derived from two animals fitted with FastLoc ${ }^{\mathrm{TM}}$ GPS tags. It is hoped that these data serve as a baseline for future studies on this little known hawksbill turtle feeding aggregation.

\section{MATERIALS AND METHDDS}

\section{Public sighting records}

Public sightings schemes are increasingly being used to rapidly gather large volumes of data on the spatial and temporal distribution of wildlife (e.g. Witt et al., 2012). Although such approaches are frequently limited by a lack of correction for survey effort, by drawing on a large body of volunteer observers they allow species distributions to be mapped more efficiently than would be feasible for professional scientists alone. This type of participatory 'citizen science' can also be an effective means of building public engagement in biodiversity research and conservation (Silvertown, 2009). In 2003, the Ascension Island Government Conservation Department (AIGCD) launched a scheme whereby divers, hikers and other members of the public were encouraged to report sightings of hawksbill turtles made around the Island. Reporting was managed through a standard form that was made available at the Department's visitor centre, along with annotated photographs offering guidance on how to distinguish between the two species of marine turtles found in Ascension Island's coastal waters (green and hawksbill). Since juvenile green turtles are rare visitors to Ascension Island's waters (with only a single verified report), we are confident that the majority of observers were able to distinguish between the two species based on size alone. Indeed, correct identifications were confirmed in photographs submitted by regular divers and snorkellers from whom the majority of sightings originated. Observers were asked to record a range of basic information relating to their sighting including the date, location, depth (for divers) and the number of turtles seen. Locations could be reported as a GPS coordinate, marked on a map or given as a geographical description which was then assigned the nearest coordinate from a standard gazetteer. To minimize duplication, sightings reported from the same date and location were treated as a single record.

\section{Tag and release}

In parallel with the public sightings scheme, a number of recreational divers also participated in an in-water tagging programme aimed at gathering information on hawksbill turtle 
residence times and growth rates. Turtles were captured opportunistically by divers using SCUBA equipment and brought to the shore where they were transferred to AIGCD staff. Once ashore, curved carapace length (CCL) and curved carapace width (CCW) of each turtle were measured to the nearest $0.5 \mathrm{~cm}$ using a flexible tape. We defined CCL as the distance between the anterior point of the nuchal scute and the posterior tip of the supracaudals measured along the midline (i.e. notch-to-tip), and CCW as width at the widest point. Turtles were checked for existing tags and, where absent, were fitted with an Inconel metal flipper tag on the trailing edge of each fore flipper and a unique Passive Integrated Transponder (PIT Tag) implanted subcutaneously into the dorsal surface of the neck. Tissue biopsies were also taken for a population genetic study that is reported elsewhere (Putman et al., 2014). Turtles were then released as close as possible to the original capture location. For those turtles that were captured more than once, we calculated displacement as the minimum straight line coastal distance (i.e. avoiding land) between first and last capture locations using QGIS v.2.o.1. We calculated annual growth rate as the CCL size increment (in $\mathrm{cm}$ ) divided by the number of days since first capture, multiplied by 365 .

\section{Satellite telemetry and home range analysis}

To supplement the in-water tagging programme, in September 2013 two juvenile hawksbill turtles were also fitted with Wildlife Computers SPLASH10 Argos-linked GPS tags allowing their movements and habitat use to be examined in greater detail. Turtles were captured by volunteer divers and taken to the shore where Fastloc ${ }^{\mathrm{TM}}$ GPS tags were affixed to the carapace using Power-Fast ${ }^{\mathrm{TM}}$ marine epoxy. Attachment sites were cleared of epibionts (algae and barnacles), lightly sanded and degreased with acetone prior to tag application. Although efforts were made to return tagged turtles to the exact point of capture, an inaccurate position given by divers resulted in one turtle being released approximately $4 \mathrm{~km}$ from its capture location. Following its release, this turtle embarked upon a period of coastal travel lasting approximately seven days before occupying a new territory where it remained until tag transmissions ceased 80 days later. Positions recorded during the period of directional travel were therefore excluded from subsequent home range analyses. GPS data were collated and downloaded using SEATURTLE.ORG's Satellite Tracking and Analysis Tool (Coyne \& Godley, 2005) and decoded using Wildlife Computers' proprietary DAP Processor software. Argos positions were not used for home range analysis as the spatial resolution has been shown to be inadequate for inferring fine-scale movements of sea turtles (Weber et al., 2013).

In order to minimize spatial autocorrelation in home range analyses we calculated mean daily locations for each turtle using the Vector Analysis Tools in QGIS v.2.0.1 (Hart et al., 2012). Home ranges were then estimated from daily mean coordinates using minimum convex polygon (MCP) and fixed kernel density (FKD) estimators implemented in the adehabitatHR package for R v.2.15.3 (Calenge, 2006). The MCP method calculates the smallest polygon enclosing the recorded positions of an animal (Burt, 1943). This approach has been used extensively for marine turtle home range analysis (e.g. Van Dam \& Diez, 1998; Seminoff et al., 2002; Scales et al., 2011; Berube et al., 2012), but is limited by its inability to reveal fine-scale patterns of habitat use within an area of residence. In contrast, the FKD estimator is a probabilistic, non-parametric method which calculates the smallest area in which an animal has a given probability of being located, and can therefore be used to identify areas with different intensities of activity (Worton, 1989; Seminoff et al., 2002; Hart et al., 2012). To facilitate comparisons with previous studies we report the total area used by each animal (i.e. 'residence areas') as the $100 \% \mathrm{MCP}$ and define 'core use areas' within these as the 50\% UDs from FKD analysis (Seminoff et al., 2002; Scales et al., 2011; Hart et al., 2012; Carrión-Cortez et al., 2013). We used the least-squares crossvalidation (LSCV) method to select the most appropriate smoothing parameter $(h)$ for the FKD analysis (Worton, 1989), and set the coastline as a physical barrier that animals were unable cross in order to correct for potential boundary biases in the estimation process (Benhamou \& Cornelis, 2010). To facilitate comparisons with previous studies we fit models with and without the boundary constraint. Mean water depths within residence areas and core use areas were extracted from a bathymetric raster layer generated by B-spline interpolation of point depths digitized from Admiralty charts using SAGA GIS v.2.o.8.

\section{RESULTS}

Between 2003 and 2013 a total of 221 hawksbill turtle sightings were reported to AIGCD by members of the public. Although these reports were inevitably biased towards popular diving, swimming and hiking areas, particularly in the north and north-west of the Island, sightings data suggest an island-wide distribution in inshore waters (Figure 2A). Sightings occurred in all months and, with the exception of a peak in February, were broadly consistent throughout the year (Figure $2 \mathrm{~B}$ ). This peak coincided with visits of a particularly active pair of volunteers and is almost certainly an artefact (see Figure $2 \mathrm{~B}$ ). In cases where bathymetry was reported by divers $(\mathrm{N}=45)$, average water depth at which sightings occurred was $13.8 \mathrm{~m}$ with a maximum depth of $34 \mathrm{~m}$. Several divers also recorded feeding behaviour. One observer reported seeing a hawksbill grazing on 'weed' growing on a rocky reef, and there were multiple reports of turtles feeding on a locally-abundant encrusting sponge that is thought to be a Ulosa species (Dr C. Goodwin, National Museums Northern Ireland, personal communication). Casual observations of turtles feeding over complex bottom types can be misleading. However, these anecdotal reports are broadly consistent with the expected foraging ecology of neritic hawksbills (Meylan, 1988). More unusually, groups of 2-6 juvenile hawksbills were also frequently observed foraging at night around the Island's pier aided by waterfront spotlighting. Night dives carried out in this area confirmed that turtles were scavenging the carcasses of large pelagic fish (predominantly tuna species) discarded by fishermen.

In addition to public sightings, a total of 35 hawksbill turtles were captured and tagged between 2003 and 2013 . The notch-to-tip curved carapace lengths of captured turtles ranged from 33.5 to $85 \mathrm{~cm}$, with an average of $48.8 \pm$ $2.0 \mathrm{~cm}$ (Figure 3). Four tagged turtles were subsequently recaptured at least once and one was recaptured on three occasions. The average time between tagging and final recapture was $1536 \pm 382$ days during which turtles grew at an 

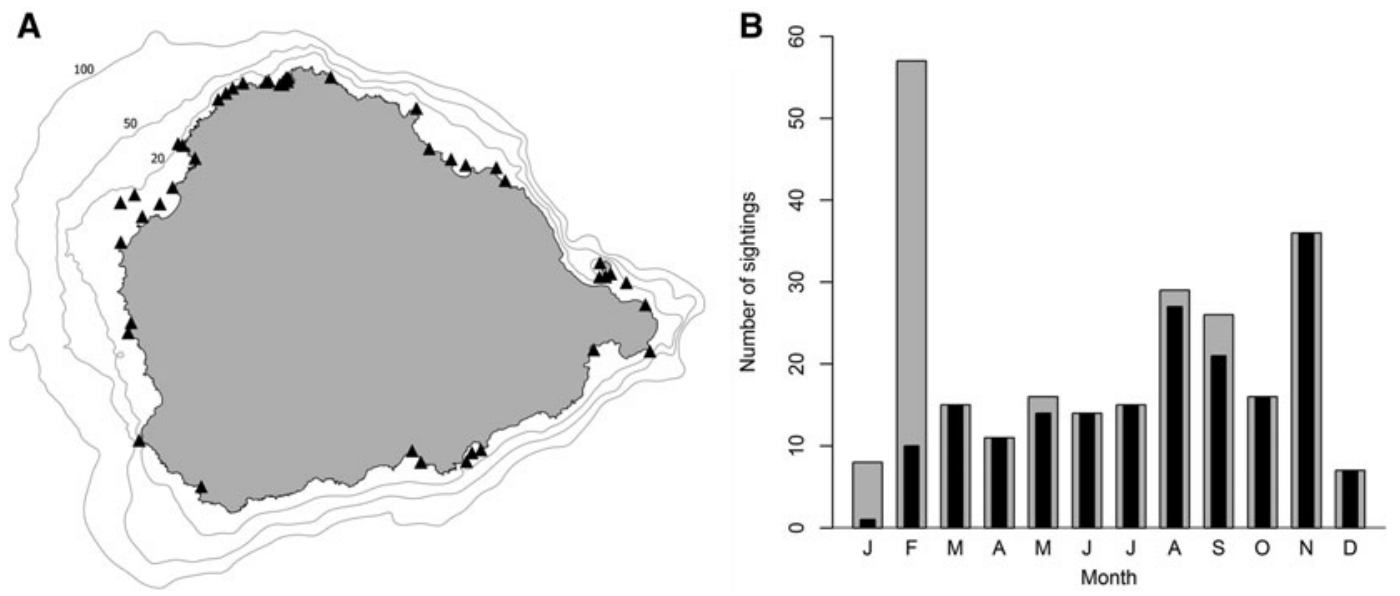

Fig. 2. Spatio-temporal distribution of hawksbill turtle sightings at Ascension Island between 2003 and 2013: (A) shows the geographical locations of public sightings reported to the Ascension Island Government Conservation Department (isobaths in metres); (B) shows sightings pooled by month. Grey bars were drawn using the entire dataset while black bars exclude sightings reported by one particularly active pair of volunteers.

average rate of $2.84 \mathrm{~cm} \mathrm{yr}^{-1} \mathrm{CCL}$ (Table 1). Despite long residence times, individuals were generally recaptured close to the site where they were first encountered, with an average displacement of $940 \pm 372 \mathrm{~m}$ (Table 1). Data from turtles fitted with Fastloc GPS devices also indicated extended residence times and a high level of site fidelity (Figure 4). GPS-tagged individuals were deliberately selected to be at the upper range of sizes found at Ascension Island in the hope of capturing their onward migrations (CCLs of 56.5 and $71 \mathrm{~cm}$ ). However, both turtles remained in Ascension's waters for the duration of the study ( $>90$ days) during which time they occupied restricted home ranges $(100 \%$ minimum convex polygons) with an average area of $2.55 \mathrm{~km}^{2}$ (Figure 4). Core use areas (50\% utilization distributions) of both turtles were less than 10 hectares (Figure 4). Fixing the coastline as a physical barrier in FKD analyses had no effect on the estimated core use area for turtle A, but marginally reduced the estimated area for turtle B from 0.6 hectares to 0.5 hectares. Mean water depth within residence areas was $13.5 \pm 0.21 \mathrm{~m}$ (range $=0-45 \mathrm{~m}$ ) and $3.3 \pm 0.13 \mathrm{~m}$ (range $=0-13.7 \mathrm{~m}$ ) for turtles $\mathrm{A}$ and $\mathrm{B}$,

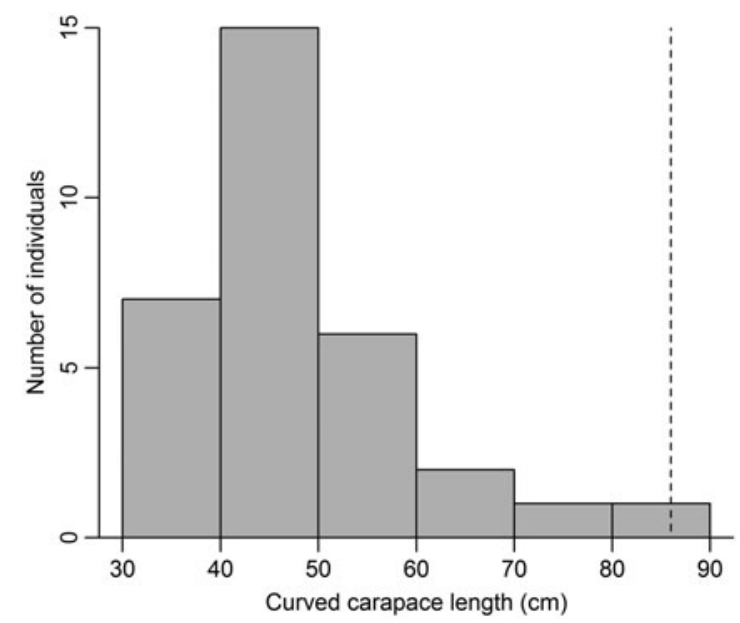

Fig. 3. Size-class distribution of hawksbill turtles captured at Ascension Island between 2003 and 2013. For comparison, the broken line shows the minimum size of adult females nesting at the South Atlantic's largest hawksbill turtle rookery in northern Bahia, Brazil (Marcovaldi et al., 1999). respectively (Figure 4), and within core use areas was $8.8 \pm$ $0.26 \mathrm{~m}$ (range $=3.8-19.6 \mathrm{~m}$ ) and $3.2 \pm 0.14 \mathrm{~m}$ (range $=$ $2-4.8 \mathrm{~m})$

\section{DISCUSSION}

There is growing evidence to suggest that a separate, immature-dominated, neritic developmental stage is a normal part of the life cycle of most chelonid sea turtles (see Meylan et al., 2011 for a recent review). Developmental habitats occupied during this time can be characterized by: (1) the exclusive or near-exclusive presence of post-pelagic, benthicfeeding juvenile animals; (2) a non-transient population exhibiting a high degree of site fidelity; and (3) a mixed-stock composition comprising individuals from multiple nesting grounds (Meylan et al., 2011). Although somewhat limited at present, the available behavioural, morphological and population genetic data for the hawksbill turtle feeding aggregation at Ascension Island are consistent with this definition (this study; Putman et al., 2014).

Hawksbill turtles recruit to Ascension Island's coastal waters at a minimum curved carapace length of approximately $33 \mathrm{~cm}$ and there are few individuals larger than $80 \mathrm{~cm}$ (Figure 3). Given that the minimum reported size of adult

Table 1. Summary of capture data, biometrics and growth rates for four juvenile hawksbill turtles recaptured at least once during the study.

\begin{tabular}{lllllc}
\hline ID & $\begin{array}{l}\text { Capture } \\
\text { date }\end{array}$ & $\begin{array}{l}\text { CCL } \\
(\mathbf{c m})\end{array}$ & $\begin{array}{l}\text { Time at } \\
\text { large (days) }\end{array}$ & $\begin{array}{l}\text { Growth rate } \\
\left(\mathbf{c m ~ y r}^{-1}\right)^{*}\end{array}$ & $\begin{array}{l}\text { Displacement } \\
(\mathbf{m})^{*}\end{array}$ \\
\hline 1 & $22 / 09 / 2003$ & 39 & - & - & - \\
& $25 / 07 / 2006$ & 45 & 1037 & 2.11 & 196 \\
2 & $07 / 02 / 2004$ & 54 & - & - & - \\
& $12 / 06 / 2004$ & 56.5 & 126 & 7.24 & 0 \\
& $24 / 10 / 2004$ & 59 & 260 & 7.02 & 325 \\
& $10 / 06 / 2007$ & 69 & 1219 & 4.49 & 920 \\
3 & $07 / 03 / 2004$ & 48 & - & - & - \\
& $03 / 07 / 2007$ & 52 & 1213 & 1.20 & 686 \\
4 & $28 / 11 / 2004$ & 38 & - & - & - \\
& $26 / 03 / 2012$ & 64 & 2675 & 3.55 & 1960 \\
\hline
\end{tabular}

*, since first encounter. 

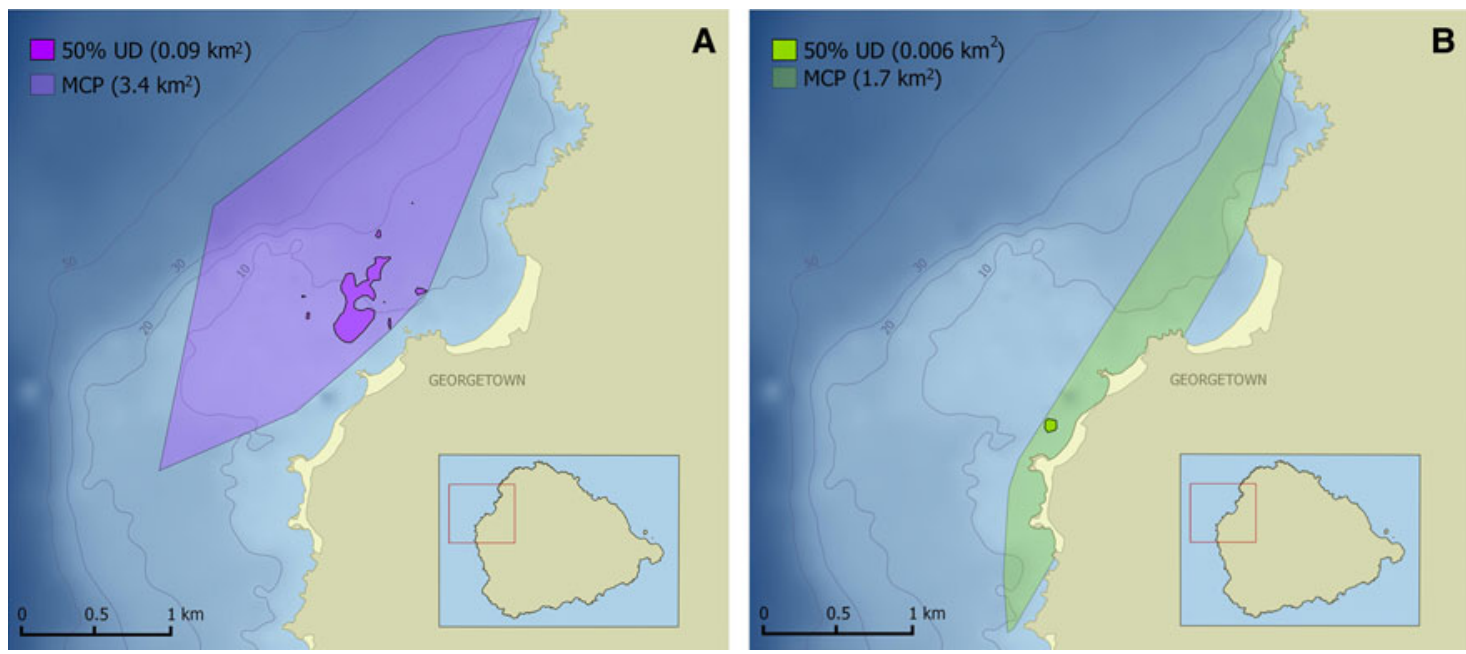

Fig. 4. Habitat use of two juvenile hawksbill turtles fitted with FastLoc ${ }^{\mathrm{TM}}$ GPS transmitters. Home ranges are displayed as $100 \%$ minimum convex polygons (MCPs) and 'core use areas' are defined as 50\% utilization distributions (UDs) from fixed kernel density analysis (i.e. the smallest areas in which turtles have a $50 \%$ probability of being located). Curved carapace lengths of turtles A and B were 71 and $56.5 \mathrm{~cm}$, respectively, and tracking durations were 196 days and 90 days.

females nesting at the largest regional rookery in Bahia, Brazil is $86 \mathrm{~cm}$ (Marcovaldi et al., 1999), it is likely that most individuals foraging around Ascension Island are juveniles (although smaller maturation sizes have been reported elsewhere, e.g. Moncada et al., 1999). The size at which hawksbill turtles recruit to benthic developmental habitats appears to vary geographically, ranging from $20-25 \mathrm{~cm}$ in the Caribbean (Diez \& van Dam, 2002; Blumenthal et al., 2009a; Meylan et al., 2011; Hart et al., 2013; Hawkes et al., 2014) to $30-35 \mathrm{~cm}$ in the southern Atlantic and Pacific (this study; Limpus, 1992; Bellini, 1996; Proietti et al., 2012; Carrión-Cortez et al., 2013). This difference may partly reflect variation in the lengths of oceanic developmental migrations. For example, whereas the neritic feeding grounds of Ascension Island and Brazil are thought to lie at the end of long, trans-Atlantic migrations for juvenile hawksbills originating from rookeries in north-eastern Brazil (Proietti et al., 2014; Putman et al., 2014), particle drift models suggest that many neonates and young juveniles originating from Caribbean rookeries are retained within the wider Caribbean region (Blumenthal et al., 2009b) allowing recruitment to adjacent feeding habitats to occur at a relatively smaller size. A second possibility is that neritic juvenile hawksbills in Brazil and Ascension Island have already spent time at an initial developmental habitat elsewhere and are, therefore, larger on average than their Caribbean counterparts (e.g. Wood et al., 2013). Indeed, further studies may reveal as yet un-described hawksbill developmental habitats within the South Atlantic region. For example, juvenile hawksbills are known to occur in the coastal waters of St Helena, $1300 \mathrm{~km}$ to the south-east of Ascension Island (Ashmole \& Ashmole, 2000), but the population has never been studied and no size-class data exist.

Studies in benthic developmental habitats in the Caribbean and Pacific suggest that post-pelagic, juvenile hawksbills have an adult-type diet, dominated by sponges, tunicates and anthozoans, along with some algae and other animal material (Meylan, 1988; Blumenthal et al., 2009a; Berube et al., 2012; Carrión-Cortez et al., 2013; Hart et al., 2013). Although quantitative data for Ascension Island are lacking, anecdotal reports from divers broadly conform to this archetype. Hawksbills were observed grazing over rocky reefs with encrusting Ulosa sponges and benthic macroalgae apparently featuring in their diets. In addition, we also documented a potentially novel nocturnal feeding behaviour, with groups of 2-6 turtles routinely taking advantage of manmade waterfront illuminations to feed on fish discards around the Island's pier. The use of anthropogenic lighting to continue foraging at night has been documented in various diurnal species (e.g. Dwyer et al., 2013), but we are not aware of any such reports for sea turtles. Scavenging, although once thought to be the predominant feeding mode of hawksbill turtles (Witzell, 1983), is also now considered to be a rare addition to a highly-specialized, largely spongiverous diet (Meylan, 1988). Nocturnal scavenging on protein-rich fish carcasses may yield nutritional and energetic benefits for young turtles, but this habit also creates potential conflicts with fisherman using the pier at night. Indeed, the AIGCD have received a number of anecdotal reports of juvenile hawksbills being inadvertently hooked or ensnared in line in this area. Adjustments to lighting fixtures along with better education on avoiding and responding to the incidental capture of turtles may help to mitigate this threat in future.

Early work on the benthic developmental stage of marine turtles assumed that post-pelagic juveniles were largely itinerant (Carr, 1980). However, subsequent studies have shown that young turtles frequently reside in developmental habitats for periods of several years and occupy well-defined territories (Van Dam \& Diez, 1998; Blumenthal et al., 2009a; Scales et al., 2011; Hart et al., 2012, 2013; Carrión-Cortez et al., 2013; Wood et al., 2013). Indeed, tagged juvenile hawksbills recaptured at Ascension Island had residence times ranging from 2 to 7 years and were generally encountered less than $1 \mathrm{~km}$ from their original capture location. A high level of site fidelity was also corroborated by GPS tracking of two large individuals which occupied restricted home ranges with an average area of $2.5 \mathrm{~km}^{2}$, and had core use areas (in which $50 \%$ of daily locations were recorded) of less than $0.1 \mathrm{~km}^{2}$ (Figure 4 ). Relatively few studies have quantified home range size for juvenile hawksbill turtles and estimates vary considerably, 
Table 2. Reported home range sizes for juvenile hawksbill turtles in benthic developmental habitats. Abbreviations for estimation methods follow Figure 4.

\begin{tabular}{llllccc}
\hline Location & Home range $\left(\mathbf{k m}^{2}\right)$ & Estimation method & Tracking method & Number of turtles & Duration (days) & Source \\
\hline Puerto Rico & $0.07-0.21$ & MCP & Acoustic & 3 & $11-16$ & {$[1]$} \\
Florida Keys & $9.2-21.5$ & $50 \%$ UD & Acoustic, PTT & 3 & $263-699$ & {$[2]$} \\
Belize & $0.05-4.0$ & MCP & Acoustic & 17 & $6-25$ & {$[3]$} \\
Roatán, Honduras & $0.15-0.55$ & MCP & VHF & 6 & $15-60$ & {$[4]$} \\
Nicoya, Costa Rica & $0.15-1.3$ & $95 \%$ UD & Acoustic & 12 & $14-30$ & {$[5]$} \\
Ascension Island & $1.7-3.4$ & MCP & GPS & 2 & $90-196$ & {$[6]$} \\
& $0.006-0.09$ & $50 \%$ UD & & & & \\
\hline
\end{tabular}

Sources: [1] Van Dam \& Diez (1998); [2] Hart et al. (2012); [3] Scales et al. (2011); [4] Berube et al. (2012); [5] Carrión-Cortez et al. (2013); [6] this study.

ranging from $0.05 \mathrm{~km}^{2}$ to more than $20 \mathrm{~km}^{2}$ (Table 2). This may in part reflect the wide range of tracking methodologies, study durations and sample sizes used (Table 2). Nevertheless, despite significant intraspecific variation, estimated home range sizes for juvenile hawksbills appear to be substantially lower than those reported for similarly sized green and loggerhead turtles (Renaud \& Carpenter, 1994; Seminoff et al., 2002; Godley et al., 2003; Barceló et al., 2013), perhaps reflecting differences in the abundance, density and/or energetic content of prey items exploited by these species.

The onset of maturity is thought to trigger the departure of marine turtles from juvenile developmental habitats (Meylan et al., 2011) meaning that residence times in these areas are likely to be significantly influenced by somatic growth rates. The mean growth rate of $2.8 \mathrm{~cm} \mathrm{yr}^{-1}$ for juvenile hawksbills at Ascension Island is close to the species average (see Hawkes et al., 2014 for a recent review), being very similar to rates reported for feeding aggregations in Florida (2.9 $\mathrm{cm} \mathrm{yr}^{-1}$; Wood et al., 2013), the Cayman Islands (3 $\mathrm{cm} \mathrm{yr}^{-1}$; Blumenthal et al., 2009a) and Mona Island, Puerto Rico (2.6-3.7 $\mathrm{cm} \mathrm{yr}^{-1}$; Diez \& van Dam, 2002). Significantly lower growth rates have been reported in Australia (Chaloupka \& Limpus, 1997), and higher rates reported in the Virgin Islands (Hart et al., 2013; Hawkes et al., 2014) and at Monito Island, Puerto Rico (Diez \& van Dam, 2002), with at least part of this variation apparently due to differences in habitat quality (Diez \& van Dam, 2002). Based on the growth rates and size-class distribution reported here and a minimum age on arrival of approximately 3-4 years (Putman et al., 2014), the majority of individuals will have departed Ascension Island by the age of $16-17$ years.

This study provides the first characterization of a littleknown developmental habitat for juvenile hawksbill turtles in the central Atlantic Ocean. More than $85 \%$ of hawksbills found in Ascension Island's waters are thought to originate from nesting stocks in the western Atlantic, particularly from north-eastern Brazil, and are thought to be transported to the Island through a combination of entrainment in the south Atlantic gyre and location-dependent orientation behaviour (Putman et al., 2014). At least a proportion of these individuals then remain at Ascension Island, feeding in shallow, benthic habitats and occupying small, coastal home ranges for periods of up to 7 years or more, before completing their trans-Atlantic migrations to adult feeding habitats along the continental coastline of Brazil (Marcovaldi et al., 2012). The size of the resident population is unknown, but is probably limited by the extent of suitable habitat. Benthic-feeding, juvenile hawksbills generally forage at depths shallower than $30 \mathrm{~m}$ (this study; Hart et al., 2012;
Carrión-Cortez et al., 2013; Wood et al., 2013), giving an estimated inhabitable area of just $27 \mathrm{~km}^{2}$ at Ascension Island. When combined with estimated home range sizes, even allowing for some overlap it seems likely that the population numbers dozens rather than hundreds. Future work should focus on obtaining more quantitative measures of density, distribution and habitat preferences of hawksbill turtles feeding at Ascension Island, as well as elaborating on migratory pathways and links with regional nesting populations and adult foraging aggregations.

\section{ACKNOWLEDGEMENTS}

The authors would like to thank the numerous expeditionary groups from the British armed forces who volunteered their time to assist with the in-water tagging study, as well as all those who participated in the public sightings scheme. We are grateful to Dr Paul Brickle and to two anonymous referees for comments that significantly improved an earlier draft of the manuscript.

\section{FINANCIAL SUPPORT}

This work was supported by grants from the Overseas Territories Environment Program (grant number OTEP ASC 803) and the Darwin Initiative (grant number 19-026).

\section{REFERENCES}

Ashmole N.P. and Ashmole M.J. (2000) St Helena and Ascension Island: a natural history. Oswestry: Anthony Nelson.

Barceló C., Domingo A., Miller P., Ortega L., Giffoni B., Sales G., McNaughton L., Marcovaldi M., Heppell S. and Swimmer Y. (2013) High-use areas, seasonal movements and dive patterns of juvenile loggerhead sea turtles in the Southwestern Atlantic Ocean. Marine Ecology Progress Series 479, 235-250.

Bellini C. (1996) Reproduction and feeding of marine turtles in the Fernando de Noronha Archipelago, Brazil. Marine Turtle Newsletter $74,12-13$.

Benhamou S. and Cornelis D. (2010) Incorporating movement behavior and barriers to improve kernel home range space use estimates. Journal of Wildlife Management 74, 1353-1360.

Berube M.D., Dunbar S.G., Rützler K. and Hayes W.K. (2012) Home range and foraging ecology of juvenile Hawksbill sea turtles 
(Eretmochelys imbricata) on inshore reefs of Honduras. Chelonian Conservation and Biology 11, 33-43.

Blumenthal J.M., Abreu-Grobois F.A., Austin T.J., Broderick A.C., Bruford M.W., Coyne M.S., Ebanks-Petrie G., Formia A., Meylan P.A., Meylan A.B. and Godley B.J. (2009b) Turtle groups or turtle soup: dispersal patterns of hawksbill turtles in the Caribbean Molecular Ecology 18, 4841-4853.

Blumenthal J.M., Austin T.J., Bell C.D.L., Bothwell J.B., Broderick A.C., Ebanks-Petrie G., Gibb J.A., Luke K.E., Olynik J.R. and Orr M.F. (2009a) Ecology of hawksbill turtles, Eretmochelys imbricata on a western Caribbean foraging ground. Chelonian Conservation and Biology 8, 1-10.

Bolten A.B. (2003) Variation in sea turtle life history patterns: neritic vs. oceanic developmental stages. In Lutz P.L., Musick J.A. and Wyneken J. (eds) The biology of sea turtles. Volume 2. Boca Raton, FL: CRC Press, pp. $243-258$.

Broderick A.C., Frauenstein R., Glen F., Hays G.C., Jackson A.L., Pelembe T., Ruxton G.D. and Godley B.J. (2006) Are green turtles globally endangered? Global Ecology and Biogeography 15, 21-26.

Burt W.H. (1943) Territoriality and home range concepts as applied to mammals. Journal of Mammalogy 24, 346-352.

Calenge C. (2006) The package adehabitat for the R software: a tool for the analysis of space and habitat use by animals. Ecological Modelling 197, 516-519.

Carr A.F. (1980) Some problems of sea turtle ecology. American Zoologist 20, 489-498.

Carrión-Cortez J., Canales-Cerro C., Arauz R. and Riosmena-Rodríguez R. (2013) Habitat use and diet of juvenile Eastern Pacific hawksbill turtles (Eretmochelys imbricata) in the North Pacific Coast of Costa Rica. Chelonian Conservation and Biology 12, 235-245.

Chaloupka M.Y. and Limpus C.J. (1997) Robust statistical modelling of hawksbill sea turtle growth rates (southern Great Barrier Reef). Marine Ecology Progress Series 146, 1-8.

Coyne M.S. and Godley B.J. (2005) Satellite tracking and analysis tool (STAT): an integrated system for archiving, analysing and mapping animal tracking data. Marine Ecology Progress Series 301, 1-7.

Diez C.E. and van Dam R.P. (2002) Habitat effect on hawksbill turtle growth rates on feeding grounds at Mona and Monito Islands, Puerto Rico. Marine Ecology Progress Series 234, 301-309.

Dwyer R.G., Bearhop S., Campbell H.A. and Bryant D.M. (2013) Shedding light on light: benefits of anthropogenic illumination to a nocturnally foraging shorebird. Journal of Animal Ecology 82, 478485 .

Godley B.J., Lima E., Akesson S., Broderick A.C., Glen F., Godfrey M.H., Luschi P. and Hays G.C. (2003) Movement patterns of green turtles in Brazilian coastal waters described by satellite tracking and flipper tagging. Marine Ecology Progress Series 253, 279-288.

Hart K., Sartain A., Fujisaki I., Pratt H., Morley D. and Feeley M. (2012) Home range, habitat use, and migrations of hawksbill turtles tracked from Dry Tortugas National Park, Florida, USA. Marine Ecology Progress Series 457, 193-207.

Hart K.M., Sartain A.R., Hillis-Starr Z.-M., Phillips B., Mayor P.A., Roberson K., Pemberton R.A., Allen J.B., Lundgren I. and Musick S. (2013) Ecology of juvenile hawksbills (Eretmochelys imbricata) at Buck Island Reef National Monument, US Virgin Islands. Marine Biology $160,2567-2580$

Hawkes L.A., McGowan A., Broderick A.C., Gore S., Wheatley D. White J., Witt M.J. and Godley B.J. (2014) High rates of growth recorded for hawksbill sea turtles in Anegada, British Virgin Islands. Ecology and Evolution 4, 1255-1266.
Limpus C.J. (1992) The hawksbill turtle, Eretmochelys imbricata, in Queensland: population structure within a southern Great Barrier Reef feeding ground. Wildlife Research 19, 489-505.

Mansfield K.L., Wyneken J., Porter W.P. and Luo J. (2014) First satellite tracks of neonate sea turtles redefine the "lost years" oceanic niche. Proceedings of the Royal Society, B 281, 20133039. doi:10.1098/ rspb.2013.3039.

Marcovaldi M., Lopez G., Soares L. and López-Mendilaharsu M. (2012) Satellite tracking of hawksbill turtles Eretmochelys imbricata nesting in northern Bahia, Brazil: turtle movements and foraging destinations. Endangered Species Research 17, 123-132.

Marcovaldi M.A., Vieitas C.F. and Godfrey M.H. (1999) Nesting and conservation management of hawksbill turtles (Eretmochelys imbricata) in Northern Bahia, Brazil. Chelonian Conservation and Biology 3, 301-307.

Meylan A.B. (1988) Spongivory in hawksbill turtles: a diet of glass. Science 239, 393-395.

Meylan P.A., Meylan A.B. and Gray J.A. (2011) The ecology and migrations of sea turtles. 8. Tests of the developmental habitat hypothesis. Bulletin of the American Museum of Natural History 357, 1-70.

Moncada F., Carrillo E., Saenz A. and Nodarse G. (1999) Reproduction and nesting of the hawksbill turtle, Eretmochelys imbricata, in the Cuban archipelago. Chelonian Conservation and Biology 3, 257-263.

Monzón-Argüello C., Loureiro N.S., Delgado C., Marco A., Lopes J.M., Gomes M.G. and Abreu-Grobois F.A. (2011) Príncipe island hawksbills: genetic isolation of an eastern Atlantic stock. Journal of Experimental Marine Biology and Ecology 407, 345-354.

Monzón-Argüello C., Rico C., Marco A., López P. and López-Jurado L.F. (2010) Genetic characterization of eastern Atlantic hawksbill turtles at a foraging group indicates major undiscovered nesting populations in the region. Journal of Experimental Marine Biology and Ecology 387, 9-14.

Mortimer J.A. and Donnelly M. (2008) Eretmochelys imbricata. In IUCN 2013. The IUCN Red List of Threatened Species. Version 2013.2. Available at: http://www.iucnredlist.org (accessed 8 August 2014).

Musick J.A. and Limpus C.J. (1997) Habitat utilisation and migration in juvenile sea turtles. In Lutz P.L. and Musick J.A. (eds) The biology of sea turtles. Volume 1. Boca Raton, FL: CRC Press, pp. 137-164

Proietti M.C., Reisser J., Marins L.F., Rodriguez-Zarate C., Marcovaldi M.A., Monteiro D.S., Pattiaratchi C. and Secchi E.R. (2014) Genetic structure and natal origins of immature hawksbill turtles (Eretmochelys imbricata) in Brazilian waters. PLoS ONE 9, e88746. doi:10.1371/ journal.pone.0088746.

Proietti M.C., Reisser J. and Secchi E.R. (2012) Foraging by immature hawksbill sea turtles at Brazilian islands. Marine Turtle Newsletter $135,4-6$.

Putman N.F., Abreu-Grobois F.A., Broderick A.C., Ciofi C., Formia A., Godley B.J., Stroud S., Pelembe T., Verley P. and Williams N. (2014) Numerical dispersal simulations and genetics help explain the origin of hawksbill sea turtles in Ascension Island. Journal of Experimental Marine Biology and Ecology 450, 98-108.

Putman N.F. and Naro-Maciel E. (2013) Finding the "lost years" in green turtles: insights from ocean circulation models and genetic analysis. Proceedings of the Royal Society, B 280, 20131468.

Renaud M.L. and Carpenter J.A. (1994) Movements and submergence patterns of loggerhead turtles (Caretta caretta) in the Gulf of Mexico determined through satellite telemetry. Bulletin of Marine Science 55, $1-15$.

Seminoff J.A., Resendiz A. and Nichols W.J. (2002) Home range of green turtles Chelonia mydas at a coastal foraging area in the Gulf of California, Mexico. Marine Ecology Progress Series 242, 253-265. 
Scales K.L., Lewis J.A., Lewis J.P., Castellanos D., Godley B.J. and Graham R.T. (2011) Insights into habitat utilisation of the hawksbill turtle, Eretmochelys imbricata (Linnaeus, 1766), using acoustic telemetry. Journal of Experimental Marine Biology and Ecology 407, 122129

Silvertown J. (2009) A new dawn for citizen science. Trends in Ecology and Evolution 24, 467-471.

Van Dam R.P. and Diez C.E. (1998) Home range of immature hawksbill turtles (Eretmochelys imbricata) at two Caribbean islands. Journal of Experimental Marine Biology and Ecology 220, 15-24.

Vilaça S.T., Lara-Ruiz P., Marcovaldi M.A., Soares L.S. and Santos F.R (2013) Population origin and historical demography in hawksbill (Eretmochelys imbricata) feeding and nesting aggregates from Brazil. Journal of Experimental Marine Biology and Ecology 446, 334-344.

Weber N., Weber S.B., Godley B.J., Ellick J., Witt M. and Broderick A.C. (2013) Telemetry as a tool for improving estimates of marine turtle abundance. Biological Conservation 167, 90-96.

Witherington B., Hirama S. and Hardy R. (2012) Young sea turtles of the pelagic Sargassum-dominated drift community: habitat use, population density, and threats. Marine Ecology Progress Series 463, 1-22.

Witt M.J., Hardy T., Johnson L., McClellan C.M., Pikesley S.K., Ranger S., Richardson P.B., Solandt J.L., Speedie C., Williams R. and
Godley B.J. (2012) Basking sharks in the northeast Atlantic: spatiotemporal trends from sightings in UK waters. Marine Ecology Progress Series 459, 121-134.

Witzell W.N. (1983) Synopsis of biological data on the hawksbill turtle Eretmochelys imbricata (Linnaeus, 1766). FAO Fisheries Synopsis 137. Rome: FAO.

Wood L.D., Hardy R., Meylan P.A. and Meylan A.B. (2013) Characterization of a hawksbill turtle (Eretmochelys imbricata) foraging aggregation in a high-latitude reef community in southeastern Florida, USA. Herpetological Conservation and Biology 8, 258-275.

and

Worton B.J. (1989) Kernel methods for estimating the utilization distribution in home-range studies. Ecology 70, 164-168.

\section{Correspondence should be addressed to:}

S.B. Weber

Ascension Island Government Conservation Department Georgetown, Ascension Island, South Atlantic Ocean, ASCN $1 \mathrm{ZZ}$

email: sam.weber@ascension.gov.ac 